International Research Journal of Management, IT \& Social Sciences
Available online at https://sloap.org/journals/index.php/irjmis/
Vol. 5 No. 2, March 2018, pages: 146 154
ISSN: 2395-7492
https://doi.org/10.21744/irjmis.v5n2.63

\title{
Internet of Things: An Applied Research on Automation for Lock Shield
}

Antonio Carlos Bento ${ }^{a}$

Article history:

Received: 25 July 2017

Revised: 18 January 2018

Approved: 10 February 2018

Published: 14 February 2018

\section{Keywords:}

Gate;

Project;

Process;

Arduino;

Automation;

\begin{abstract}
This study presents results obtained in applied research, involving controller boards (Arduino), at the Nove de Julho higher education institution, in the courses of Computer Science in São Paulo. In 2018, focusing mainly on the positive and negative points presented by the statistical data of the public security office. The methodology used to obtain the data was experimental research based on results obtained in the newspaper Estadão of June 25, 2017. Every hour, a house is invaded in the State of São Paulo, according to data of the Public Security Secretariat, focusing mainly in the qualitative and quantitative results, seeking greater security for homes with tilting gates, avoiding fraud and cloning of locks. Creating new automation equipment, focused on security, its assembly is more complex and more structured than the simple control boards and controls for swing gates. Thus obtaining a safer drive with a high power against fraud, since the system is mounted on top of the controller boards (Arduino), this system achieved a higher degree of reliability than conventional systems.
\end{abstract}

2395-7492@ Copyright 2018. The Author. This is an open-access article under the CC BY-SA license (https://creativecommons.org/licenses/by-sa/4.0/) All rights reserved.

\section{Author correspondence:}

Antonio Carlos Bento,

Technologies of Intelligence and Digital Design,

Pontifícia Universidade Católica de São Paulo São Paulo, Brazil,

Email address: acb01@Hotmail.com

\section{Introduction}

The motivation for the development of this work originated from a personal experience, in which reliability problems of control plates of tilting gates were observed for the activation of electric locks. Based on a survey of the Jornal Estadão of July 25, 2017 [6], Segs [18] and SINDSEGSP [19]. Statistical data from the Secretariat of Public Security, an average of 54 properties are assaulted per day; only last year were 10,905 assaults on residences in the state of São Paulo, an index $8.5 \%$ higher than in 2015, at least one São Paulo home is invaded every hour.

The risk of cloning the electric locks of conventional gates is very high, making access easy for those who are aware of its use and operation. Since the electric lock with conventional system is connected to the control board of the swing gate motor. Based on these statistical data, one of the forms of prevention is the use of radio-activated electrical locks. Using Arduino and a radio signal amplifier, a remote control automation system for electric locks

a Pontifícia Universidade Católica de São Paulo Sâo Paulo, Brazil 
has been set up, to prevent any residence from entering the statistical numbers of the Public Security Secretariat. Its operation is based on sending an eight-digit code of the remote control to the receiving system, which will receive the signal sent and send an electric current to the lock, causing it to open.

\section{Research Methods}

This work was developed based on qualitative, bibliographical and documentary research. Qualitative research comprises a set of interpretive techniques that aim to describe and decode the components of a complex system of meanings Marconi and Lakatos [13]. Bibliographic research covers all scientific works already made public about the topic of study, from individual publications, newsletters, newspapers, magazines, books, research, monographs, theses, etc. Its purpose is to put the researcher in direct contact with everything that was written, said or filmed on a certain subject Marconi and Lakatos [13].

The documentary analysis is an important technique in qualitative research, either complementing information obtained by other techniques, or revealing new aspects of a theme or problem. Marconi and Lakatos [13]. The research carried out, with the theoretical basis in the Arduino presented below, allowed the development of an experiment of automation of electric locks, to demonstrate a safer form of automation of such locks, without the risks of invasion, of the control plate coupled to swing gate motors.

The researchers have allowed the development of an experiment of experimental type, observing the problems of the control boards of dump gate motors, which can be simply invaded with a simple universal control for gate motors, a serious fault of the system is simply eminent. Note that the operation of the boards is performed by the radio signal, thus sending a signal of a small control to the motor control board, where an electric current is sent to the motor and the electric lock. Bearing in mind that the lock does not come with the engine, it is purchased separately and installed to the output wires of the engine control plate. Since a timing plate intervenes between this connection. Therefore, there is a time limit on when the lock is triggered. It is necessary for the lock to be on for "open" time and then to be "closed" off.

Using the Arduino, an electrical scheme will be set up for the electrical automation without the use of the conventional control of swing doors; it is noted that this project is based on assembling a device that can open and close the lock without any risk of fraud in the system. Thus, a project is being constructed that will have two physical parts, one being an electrical scheme using the Arduino. It replaces the use of the conventional control board of swing gates, for the activation and control of the electric lock, and the other physical part is the control that will also be mounted using the Arduino to communicate with the new control board.

\section{Results and Analysis}

Considering the studies realized by the authors: Abduliah [1], CERP [3], Hgai et. al. [8], ITU-T [9], Larrucea et. al. [10], Li and Kara [11], Lin et. al. [12], Minerva [15], 17. Mukhopadhyay and Wolf [17], about the internet of things, referring to the use of different kind of devices or object connected to an internet, allowing control from long distances, and sharing data.

According to Arduino [2] "Arduino is an open-source electronics prototyping platform based on flexible, easyto-use hardware and software." The platform allows the creation of projects for several areas such as robotics, education, medicine and any other activity in which electronic processing can be used. According to Bluam [5], "The Arduino platform is composed of electronic board (hardware) and a development environment (software) to create projects by users."

There is already other hardware on the market such as Philips and recording software, such as Matlab, but the Arduino platform has its hardware and software to facilitate the work of beginners and people with little knowledge in electronics. In the words of Monk [16], "The Arduino was designed to be easy to understand, programmed, and applied, as well as operating on a variety of operating systems."

Code development software and documentation for this project can be downloaded for free from the platform's official website: https://www.arduino.cc. Like most free software, the Arduino platform is also open to suggestions for improvements. As Melo [14] notes, "Arduino platform boards can be used to develop interactive artifacts independently or connected to a computer." The two application formats follow the same operating principle of a computational system that is the interaction of the steps: input, processing, and output.

Bento, A. C. (2018). Internet of Things: An Applied Research on Automation for Lock Shield. International Research Journal of Management, IT and Social Sciences, 5(2), 146-154. https://doi.org/10.21744/irjmis.v5n2.63 


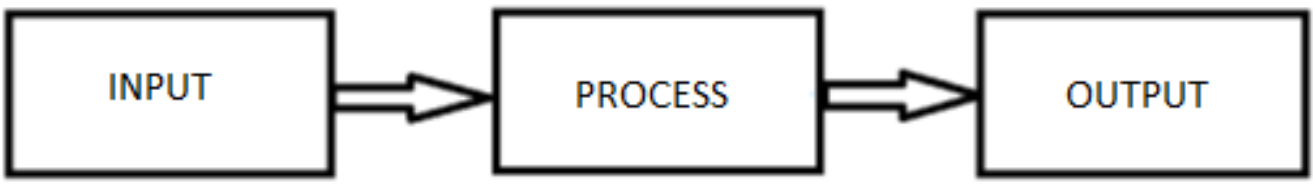

Figure 1. Fonseca and Beppu [8] computational system.

Input: it is responsible for receiving or capturing data, in Arduino systems this data can come from sensors, computers or commands sent by users.

Processing: The processing part is responsible for performing the predefined actions taking into account the data coming from the 24-input stage. In the Arduino platform, this task is performed by the microcontroller that internally stores the code with the execution rules. Output: The output of a computer system is the result of the data processing stage, in the Arduino platform these outputs can be electrical impulses that trigger equipment such as lamps and appliances or even send a message to a cell phone. As discussed in Bluam [5] "the smart element of the board is the microcontroller, it is the main component of the board because all code is stored and processed in it." Due to its importance, the microcontroller will be dealt with in more detail in the following section.

\section{Microcontroller}

As discussed by Fonseca and Beppu [8], "A microcontroller (also called MCU) is a computer on a chip, which contains processor, memory and I / O peripherals." Thus, a microcontroller is a computational system composed of the basic structures necessary to develop the work of data processing. The market has a diversity of microcontrollers with different characteristics of size, price, and processing power.

Table 1

Microcontrollers

\begin{tabular}{ccccc}
\hline Manufacturer & Microcontroller & Frequency & RAM & ROM \\
\hline Intel & $87 \mathrm{C} 51-24$ & $24 \mathrm{MHZ}$ & $256 \mathrm{~B}$ & $4 \mathrm{~KB}$ \\
\hline Philips & P87C51MB2 & $24 \mathrm{MHZ}$ & $2 \mathrm{~KB}$ & $4 \mathrm{~KB}$ \\
\hline Atmel & AT89C5115 & $40 \mathrm{MHZ}$ & $512 \mathrm{~B}$ & $18 \mathrm{~KB}$ \\
\hline Dallas & DS87C550 & $33 \mathrm{MHZ}$ & $1 \mathrm{~KB}$ & $8 \mathrm{~KB}$ \\
\hline
\end{tabular}

Adaptaded from Zelenovisky e Mendonça [20].

As presented in some studies, the increase in frequency influences the increase in processing capacity. In this way, it can be observed that the processing power of the microcontrollers is lower than the personal computers since these usually work with a frequency higher than GHz. As shown in Table 1, the working frequency range of microcontrollers is in $\mathrm{MHz}$.

As can be seen in the last two columns of Table 1, the microcontrollers have among their components the RAM and ROM memories, as well as frequency; they represent a crucial factor in the performance of microcontrollers. The RAM is the memory used by users to develop programs. Its use is restricted to the period in which the equipment is in operation. If the machine does not receive power even in a short time, all the contents of the RAM will be erased, i.e. it is a volatile memory.

According to studies, the ROM is a portion of memory that does not rely on energy to maintain its content, i.e. it is a non-volatile memory. In this way, the ROM can be used to record codes that can not be erased when the chip is de-energized. Arduino [2] "The Arduino platform uses Atmel microcontrollers, and different chip models are used to accommodate the various types of boards the platform has. Each model of the microcontrollers of the platform has different sizes of memory and frequency of processing ".

Arduino [2] states that the $\mathrm{C}$ programming language can be used to create code for Arduino platform microcontrollers. However, to facilitate the creation of the code by the users of the platform, a language of its own has been developed, as will be demonstrated in the following section. 
Arduino program language

According to Melo [14], "Because the platform is intended to be easy to learn, it is necessary to use a high-level programming language to hide the peculiarities of programmers' hardware. For this, the Arduino platform chose the $\mathrm{C} \backslash \mathrm{C}++$ language to be used as a reference, preserving its classical syntax in the declaration of variables, operators, pointers, structures and many other language features. " According to Arduino [2], Arduino programs can be divided into three main parts:

Structures: The structure comprises the control structures, arithmetic, and boolean operators. The pointers in the $\mathrm{C}$ language are also present on the Arduino platform. Values: The values cover the data types supported by the platform, it accepts most types of high-level languages such as int, float, boolean, and so on. But the difference is that it has types like high and low to declare that some pin of the chip is placed with 5 volts or 0 volts. Functions: The platform contains several functions specific to microcontrollers, for example, there are the digital and analog functions that are used to control the pins that are the input and output interface of data.

In the words of Bluam [5], Arduino codes have the peculiarity of needing two functions, setup () and loop (), which are language-specific. The setup () and loop () functions are mandatory, i.e., even if their use is not required, they should be included in the code used.

setup (): routine entered at the beginning of the program to determine the necessary settings for the program.

loop (): function executed after setup (setup ()). It will run continuously while the power is not turned off.

In Arduino's words [2] "The codes written using the Arduino development environment are called sketches, and these files are saved with extension."

The way that programs are created on the Arduino platform look like other languages like Java, the difference is that the Arduino platform needs another stage, which is the writing of the code in the microcontroller. The phases of the process of creating a program with the platform are exposed in the Figure presenting the four phases that are: create, compile, record and execute.

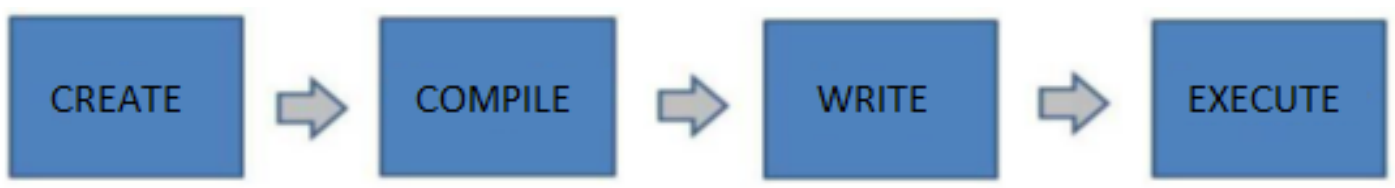

Figure 2. Development phases of an application Source: Bluam [5]

The first phase of the process presented in Figure 2 is the creation of the code by the user. At this stage, the logical structures are created, and the libraries used in the code are declared. Then the code is passed by a compiler, which, according to Arduino [2] transforms the readable code into machine instructions. As shown in Figure 2, after the code is compiled it goes to the recording phase, in that phase the program is sent from the computer to the memory of the microcontroller.

The last phase, which is the execution of the code, happens spontaneously as soon as the microcontroller is energized, this is because all Arduino code structures are written inside the loop () function. According to Arduino [2], several steps are performed in the compilation process, these steps as can be seen in Figure 3 are: verifying, transforming and joining the user code so that it is in the format in which the microcontroller can process.
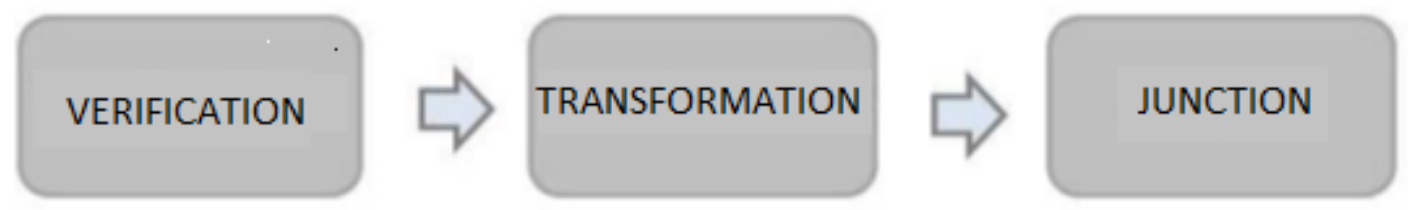

Figure 3. Compilation - Source: Bluam [5]

Bento, A. C. (2018). Internet of Things: An Applied Research on Automation for Lock Shield. International Research Journal of Management, IT and Social Sciences, 5(2), 146-154. https://doi.org/10.21744/irjmis.v5n2.63 
The compilation steps are described as follows:

Verification: In the first phase a check is performed to make sure that the code is spelled correctly; Transformation: then the code is transformed into machine language which is the format that will be written to the memory of the microcontroller. Junction: In the join phase, the user-written code is joined to the libraries used in the code. The result of the compilation process, presented in Figure 3 through the verification, transformation, and join phases, is a single file that can be sent to the chip to be written to memory.

According to Melo [14], the platform has several libraries working in areas such as serial communication, sensory and motor control. In addition, according to Arduino [2], the platform allows users to create their libraries to be used in their projects and made available to others.

Applying studies on Arduino, applications of the methodology and costs used to obtain the assembly of the project in its initial phase. It led to discussions on specific points in the project "Internet of Things: An Applied Research on Automation for Lock Shield," in which crucial points, both positive and negative, were found.

Positive points: The reliability gains of both the systemic and physical security part.

Its maintenance cost is almost zero since the system once installed correctly; there is no need for preventive maintenance. The coding of access control with the system was very well designed, an eight-digit code is sent to the radio system, which is processed and releases the magnetic lock. Negative points: Since the system is homemade rather than industrial, there is no certainty that the components that are used for its assembly will withstand indefinitely since each component is purchased separately, and from different suppliers of electronic equipment. Thus it is not possible to measure the degree of durability of the components, its only means of correcting problems is via corrective maintenance.

The results obtained from the "Internet of Things: An Automated Search for Lock Shield" project was considerably high, with a ten times greater reliability gain than conventional control plates for swing gate motors. With a complex and difficult to access fraud system, Lock Shield has achieved both reliability and affordability to the general public.

\section{Project costs}

The Lock Shield Automator design has a low cost but with some updates to the system can run more safety features like raising and lowering the swing gate controlling electric motors. The cost may rise, however, the purpose of this project is the automation of electric locks for swing doors. To have a brief idea of how much this system will cost from the beginning of the project until its completion, a small cost survey was carried out. As a table and price comparison charts of each equipment, in a survey conducted on the free market site, always prioritizing the lowest price and a good sales income at the end of the project.

Table 2

Cost Survey

\begin{tabular}{lccc}
\multicolumn{1}{c}{ Devices } & Unit Price & Quantity & $\begin{array}{c}\text { Total } \\
\text { Cost }\end{array}$ \\
\hline $\begin{array}{l}\text { Nodemcu Esp8266 V3 12e Cp2102 Wireless Wifi } \\
\text { Arduino }\end{array}$ & $\mathrm{R} \$ 21,00$ & 2 & $\mathrm{R} \$ 42,00$ \\
\hline Nrf24101 Rf Transceiver Module Ism 2.4ghz Wireless & $\mathrm{R} \$ 5,00$ & 2 & $\mathrm{R} \$ 10,00$ \\
\hline $\begin{array}{l}\text { Module Rele 2 Canais 5v 10a Srd-05 Relay Module } \\
\text { Arduino }\end{array}$ & $\mathrm{R} \$ 8,50$ & 1 & $\mathrm{R} \$ 8,50$ \\
\hline $\begin{array}{l}\text { Protoboard Syb-170 Pontos Placa Para Eletrônica } \\
\text { Arduino }\end{array}$ & $\mathrm{R} \$ 6,00$ & 1 & $\mathrm{R} \$ 6,00$ \\
\hline $\begin{array}{l}\text { Micro Usb To Hdmi Tv Av Cabo Hdtv P/ Samsung } \\
\text { Galaxy S3 }\end{array}$ & $\mathrm{R} \$ 13,00$ & 1 & $\mathrm{R} \$ 13,00$ \\
\hline $\begin{array}{l}\text { 10 Jumpers Terminais Macho X Macho Para Arduino } \\
\text { Ou Pic }\end{array}$ & $\mathrm{R} \$ 3,00$ & 1 & $\mathrm{R} \$ 3,00$ \\
\hline $\begin{array}{l}\text { Jumper Premium 40p X 20cm - Fêmea / Macho } \\
\text { Kit Com 210 Resistores De 21 Valores Diferentes }\end{array}$ & $\mathrm{R} \$ 10,00$ & 1 & $\mathrm{R} \$ 12,00$ \\
\hline $\begin{array}{l}\text { Capacitor Bipolar Eletrolítico 47uf 100v - P/ Driver } \\
\text { Corneta }\end{array}$ & $\mathrm{R} \$ 1,00$ & 1 & $\mathrm{R} \$ 12,00$ \\
\hline Cabo Adaptador Alimentação Arduino Bateria 9v & $\mathrm{R} \$ 2,00$ & 1 & $\mathrm{R} \$ 2,00$ \\
\hline
\end{tabular}




\begin{tabular}{lccc}
\hline $\begin{array}{l}\text { Battery 9v Greencell Para Arduino Postagem Em 24 } \\
\text { Hrs }\end{array}$ & \multirow{2}{*}{$\$ 5,00$} & 1 & $\mathrm{R} \$ 5,00$ \\
\hline Power Fullr 12v 1a 110/220v Arduino & $\mathrm{R} \$ 16,00$ & 1 & $\mathrm{R} \$ 16,00$ \\
\hline Lock Gate Electronics & $\mathrm{R} \$ 69,00$ & 1 & $\mathrm{R} \$ 69,00$ \\
\hline \multicolumn{2}{c}{ Total cost of the project } & & $\mathrm{R} \$$ \\
& & & 198,50 \\
\hline
\end{tabular}

Equipment to be used: a column of electronic equipment that will be used from the initial phase.

Unit Price: price column of each equipment.Quantity: a column of each respective quantity of each equipment.

Total value: total price column spent on each device, where a calculation was lifted (unit price multiplied by quantity).

For the initial phase of the project, a small cost survey resulted in $\mathrm{R} \$ 198.50$. This value is only for equipment of the initial phase of the project, not included artistry, visual part, and not even materials, like a computer for programming of the Arduino among other resources necessary for the finalization of the project.

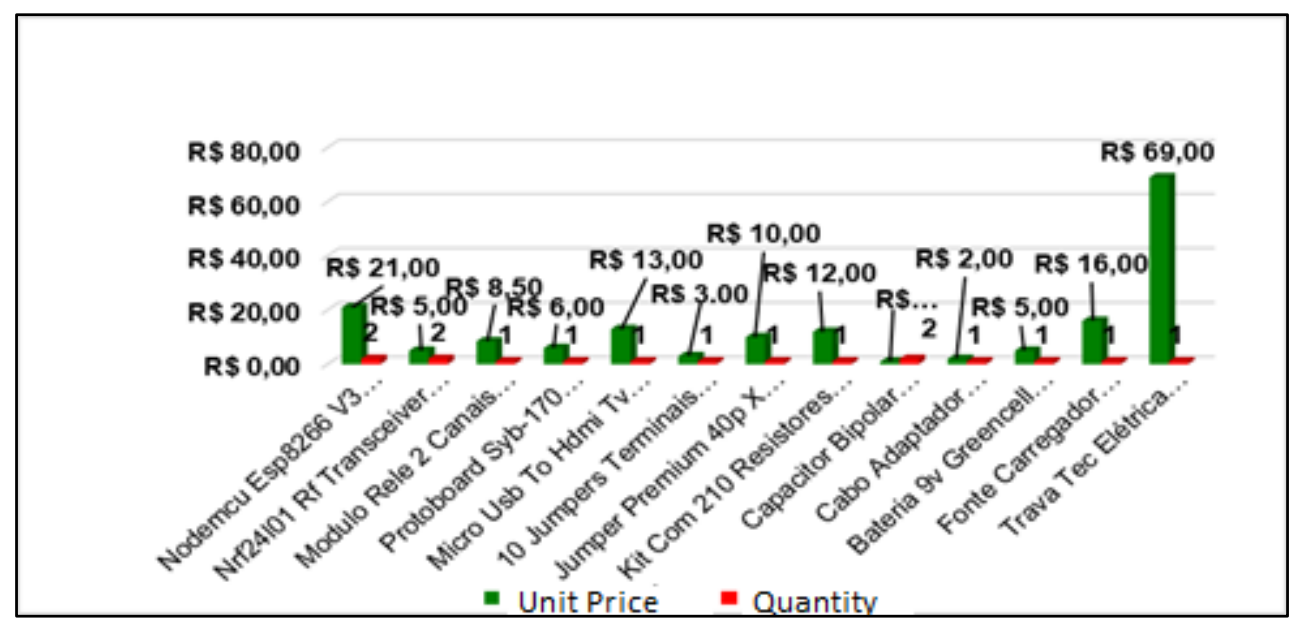

Graph 1 - Comparison of Price and Quantity of each Equipment

Unit Price: price column of each equipment.

Quantity: a column of each respective quantity of each equipment.

This graph shows the unit price difference and the quantity of each equipment to be used.

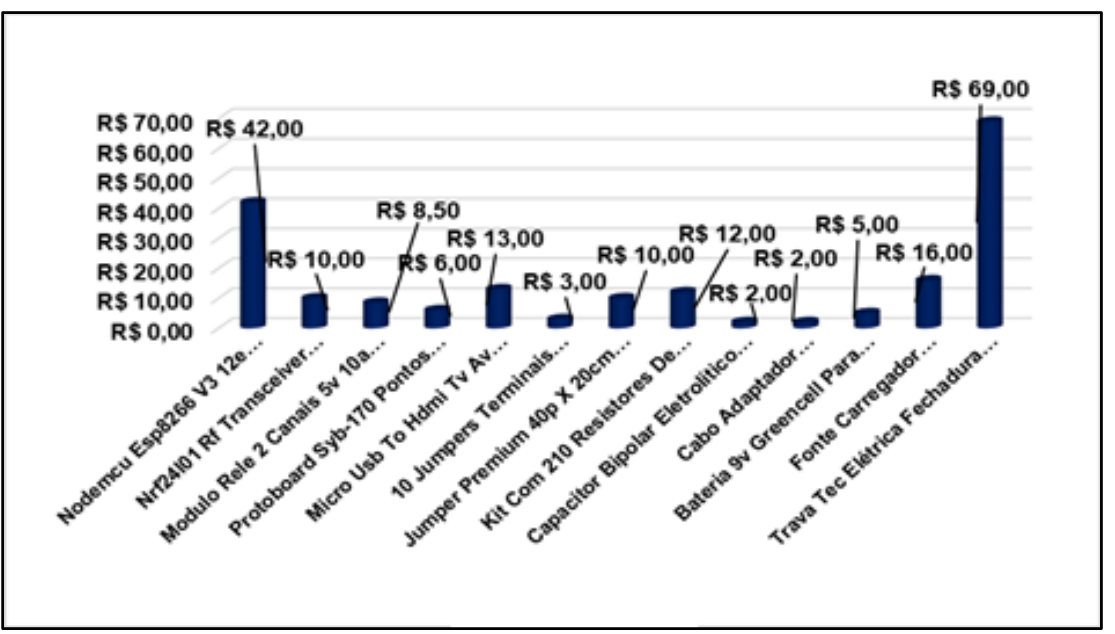

Graph 2. Comparison of Total Values.

Bento, A. C. (2018). Internet of Things: An Applied Research on Automation for Lock Shield. International Research Journal of Management, IT and Social Sciences, 5(2), 146-154. https://doi.org/10.21744/irjmis.v5n2.63 
Total value: total price column spent on each device, where a calculation was lifted (unit price multiplied by quantity). This chart demonstrates the difference in values based on the quantity of each equipment to be used in the project. Total value: total price column spent on each device, where a calculation was lifted (unit price multiplied by quantity). This chart demonstrates the difference in values based on the quantity of each equipment to be used in the project.

\section{Conclusion}

It is concluded that with the high theft rate of residences in São Paulo. The greater its prevention, the lower the risks of its property being invaded, noting that most of the basement doors in São Paulo work with common controller boards, such as plates can be easily cloned with a simple universal control, thus making the opening of the gate and the property is easily stolen.

By analyzing the safety flaws of such boards, the Lock Shield was developed, to increase the safety level of the swing gates and reduce the theft rate of residences in São Paulo. The Lock Shield is an electronic device developed based on the Arduino controller board, added, from a radio signal magnifier. The Lock Shield is divided into two physical parts, the signal receiving part is coupled to the gate motor and the signal is emitting part which performs the drive control function. Given the above facts, it is concluded that increasing the safety of swing gates is important for reducing theft of property, as Lock Shield is a great improvement in locking technology.

\section{Acknowledgements}

I would like thanking an IRJMIS editor for their advice and valuable time to complete this paper. 


\section{References}

1. Abdullah, A. G., \& Putra, A. P. (2017). Water Level Measurement Altitude Trainer Integrated With Human Machine Interface. Indonesian Journal of Science and Technology, 2(2), 197-210.

2. D’Ausilio, A. (2012). Arduino: A low-cost multipurpose lab equipment. Behavior research methods, 44(2), 305313.

3. Uckelmann, D., Harrison, M., \& Michahelles, F. (2011). An architectural approach towards the future internet of things. In Architecting the internet of things (pp. 1-24). Springer, Berlin, Heidelberg.

4. Pereira, E. H. H. (2014). Soluções inteligentes e de baixo custo para a automação residencial utilizando smartphones(Doctoral dissertation, UNIVERSIDADE DE SÃO PAULO).

5. Blum, J. J., Eskandarian, A., \& Hoffman, L. J. (2004). Challenges of intervehicle ad hoc networks. IEEE transactions on intelligent transportation systems, 5(4), 347-351.

6. Fausto, B. (1984). Crime e cotidiano: a criminalidade em São Paulo, 1880-1924. Edusp.

7. de Arruda, J. W. O. Controle Automático de Rum.

8. Ngai, E., Dressler, F., Leung, V., \& Li, M. (2017). Guest Editorial Special Section on Internet-of-Things for Smart Cities and Urban Informatics. IEEE Transactions on Industrial Informatics, 13(2), 748-750.

9. Chen, Y. K. (2012, January). Challenges and opportunities of internet of things. In Design Automation Conference (ASP-DAC), 2012 17th Asia and South Pacific (pp. 383-388). IEEE.

10. Larrucea, X., Combelles, A., Favaro, J., \& Taneja, K. (2017). Software engineering for the internet of things. IEEE Software, 34(1), 24-28.

11. Li, W., \& Kara, S. (2017). Methodology for Monitoring Manufacturing Environment by Using Wireless Sensor Networks (WSN) and the Internet of Things (IoT). Procedia CIRP, 61, 323-328.

12. Liu, Q., Zhang, H., Wan, J., \& Chen, X. (2017). An access control model for resource sharing based on the RoleBased access control intended for Multi-domain manufacturing Internet of Things. IEEE Access, 5, 7001-7011.

13. Bervian, P. A., Cervo, A. L., \& Silva, R. D. (2002). Metodologia científica. São Paulo: Pretence Hall, $482-493$.

14. Palis, J. J., \& De Melo, W. (2012). Geometric theory of dynamical systems: an introduction. Springer Science \& Business Media.

15. Minerva, R., Biru, A., \& Rotondi, D. (2015). Towards a definition of the Internet of Things (IoT). IEEE Internet Initiative, 1.

16. Monk, S. (2017). Programação com Arduino: começando com Sketches. Bookman Editora.

17. Wolf, M., \& Mukhopadhyay, S. (2017). VLSI for the Internet of Things. Computer, 50(6), 16-18.

18. de Almeida Teles, M. A., \& de Melo, M. (2017). O que é violência contra a mulher. Brasiliense.

19. SINDSEGSP - A cada 1 hora, uma casa é invadida no Estado de SP, 2017. http://www.sindsegsp.org.br/site/noticiatexto.aspx?id=28086

20.Zelenovisky, R. Mendonça, A. Arquitetura de microcontroladores modernos. http://www.mzeditora.com.br/artigos/mic_modernos.htm

Bento, A. C. (2018). Internet of Things: An Applied Research on Automation for Lock Shield. International Research Journal of Management, IT and Social Sciences, 5(2), 146-154. https://doi.org/10.21744/irjmis.v5n2.63 


\section{Biography of Author}

\begin{tabular}{||l|l|}
\hline \hline 600 & $\begin{array}{l}\text { Doctor in Cognitive Environments and Digital Design in the course of Technologies of } \\
\text { Intelligence and Digital Design of PUC-SP. He holds a Master's degree in Information } \\
\text { Systems Technology from the Fundação and Instituto de Ensino Para Osasco. He holds } \\
\text { an MBA in Information Systems from the University of São Paulo. He graduated in Data } \\
\text { Processing from Ibirapuera University and is currently a professor in undergraduate and } \\
\text { postgraduate courses. He has experience in the area of Computer Science, with emphasis } \\
\text { on Information Technology, Project Management, Database, Software Engineering, } \\
\text { Software Systems for Education, Intelligent Systems and Specialists, Security, Systems } \\
\text { Modeling and Information Technology Management. Acting on WBAN projects, } \\
\text { artificial intelligence, and information technology. }\end{array}$ \\
\hline
\end{tabular}

